\title{
The use of a nested polymerase chain reaction for detecting Pneumocystis carinii from lung and blood in rat and human infection
}

\author{
R. EVANS, A. W. L. JOSS, T. H. PENNINGTON* and D. O. HO-YEN \\ Microbiology Department, Raigmore Hospital NHS Trust, Inverness IV2 3UJ and * Medical Microbiology \\ Department, Aberdeen University, Aberdeen
}

\begin{abstract}
Summary. A nested polymerase chain reaction (PCR) assay was developed to detect both ratand human-derived Pneumocystis carinii DNA. The nested PCR product was $125 \mathrm{bp}$ long and was representative of part of the gene coding for the large subunit of mitochondrial ribosomal RNA. Twenty serial blood samples and 24 tissues from six immunosuppressed SpragueDawley rats were examined by nested PCR. All lung samples were positive by PCR and Toluidine blue $\mathrm{O}$ staining. Buffy coat samples and all the other tissues were PCR-negative during up to 6 weeks of immunosuppression. Thirty-five clinical bronchoalveolar lavage, induced sputum or tracheal aspirate samples from human patients were tested. Twelve of 35 were positive by both PCR and indirect fluorescence assay (IFA) and 19 of 35 were both PCRand IFA-negative. Four of 35 were IFA-negative but PCR-positive and there were good responses in these patients to specific therapy, indicating that PCR may be more useful than IFA in clinical samples. $P$. carinii DNA was not detected in three blood samples. The nested PCR is a sensitive and specific DNA amplification method suitable for the routine diagnosis of $P$. carinii in human respiratory samples.
\end{abstract}

\section{Introduction}

Respiratory samples have been the mainstay of the laboratory diagnosis of Pneumocystis carinii infection. The organism is routinely detected by various direct staining methods. ${ }^{1}$ Selective staining methods, such as Grocott methenamine silver, Toluidine blue $\mathrm{O}$, cresyl echt violet and Gram-Weigert are widely used. They specifically stain the cystic stage of $P$. carinii which, under ideal conditions, is easily identifiable. Other stains, such as Giemsa, Wright or Diff-Quik are rapid and easy to perform but are not selective, thus making accurate identification difficult. Immunofluorescence assays have been developed with polyclonal and monoclonal antibodies to both trophozoite and cystic stages. These methods are the most successful, but false negative results can still be a problem. ${ }^{1}$

The development of DNA amplification techniques has given rise to the extremely sensitive polymerase chain reaction (PCR) assay. The assay protocol can be varied and has been applied to detect specific $P$. carinii DNA. ${ }^{2-5}$ Single-step PCR and Southern blot hybrid- isation have been used successfully to detect $P$. carinii in clinical bronchoalveolar lavage (BAL) and induced sputum (IS) samples ${ }^{2-4}$ but there is limited information about the use of a nested PCR. ${ }^{5}$ The nested PCR assay is potentially useful as a diagnostic assay as it has a relatively short assay time compared to Southern blot hybridisation; also, it is technically easier to perform and does not involve the use of radiolabelled or expensive enzyme or chemiluminescent immunoassay probes. Three primers described by Wakefield et al. ${ }^{6}$ and previously used with a single-step PCR and Southern blot hybridisation assay were used in this study. These primers are part of the gene coding for the large subunit of the mitochondrial ribosomal RNA, they are highly specific for $P$. carinii DNA and do not amplify DNA from other potential pulmonary pathogens. ${ }^{6}$ The rat model was used to develop the assay, as disease progression is similar to that for human infection. It was hoped to develop a sensitive PCR technique to improve our understanding of infection in the rat and to determine the usefulness of the technique for human samples. 


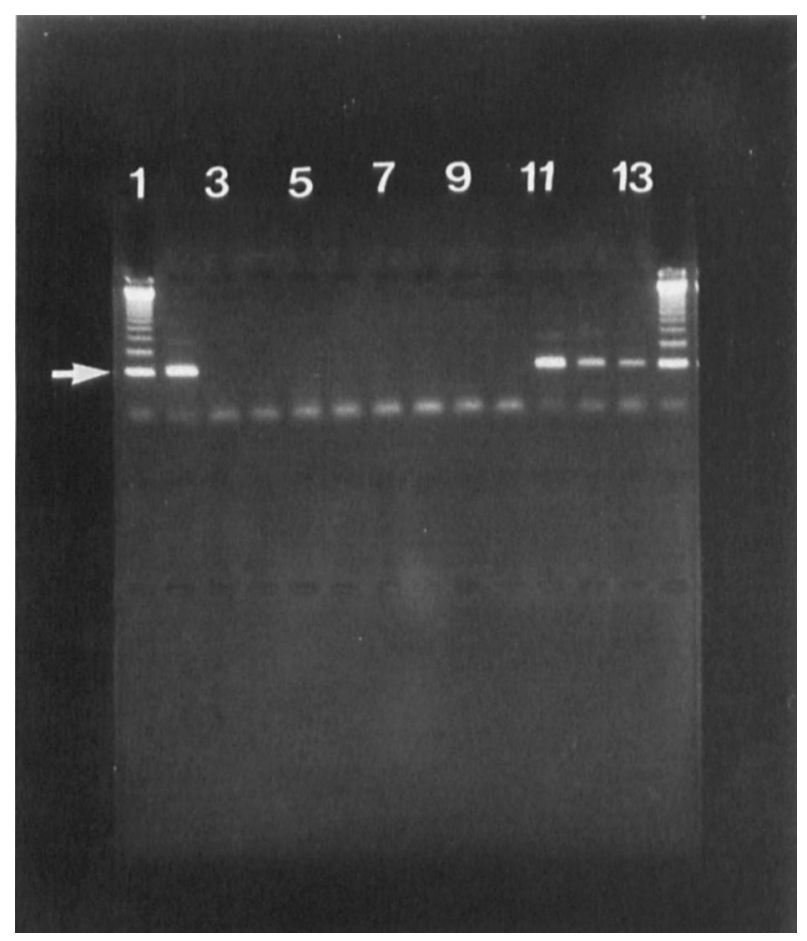

Figure. Electrophoresis gel demonstrating nested PCR run of samples of human and rat $P$. carinii and other potential pulmonary organisms. Lanes 1 and 14, 123-bp ladder (arrow); 2, humanderived $P$. carinii; 3 and 10, negative control (SDW); 4, S. aureus; $5, K$. pneumoniae; 6, C. albicans; $7, C$. tropicalis; 8 , adenovirus; 9, $T$. gondii; 11, $1 \mathrm{ng}$ of rat-derived $P$. carinii positive control; $12,100 \mathrm{pg}$ positive control; $13,10 \mathrm{pg}$ positive control.

\section{Materials and methods}

\section{Sample preparation}

$P$. carinii infection was induced in 6-week-old Sprague-Dawley rats by immunosuppression with hydrocortisone i.m. $(2 \times 0.5 \mathrm{ml}, 25 \mathrm{mg} / \mathrm{ml}$, Boots Pharmaceuticals) twice weekly. ${ }^{7}$ Animals were treated throughout with tetracycline and penicillin orally. Tail bleeds were taken into lithium-heparin-coated capillary tubes $(5-40 \mu \mathrm{l})$ at specific time intervals after immunosuppression. Haemoglobin was removed by hypotonic lysis and the leucocyte pellet washed twice in sterile distilled water (SDW). Rats were killed with pentobarbitone i.p. (Veterinary Drug Co. plc, York) $1.5 \mathrm{ml}$ at 6 weeks post-infection. Blood, lung, liver, kidney and spleen were collected. The level of $P$. carinii infection in the lung was assessed by examining stained lung imprints. Buffy coats were separated on Histopaque 1077 (Sigma) with centrifugation at $400 \mathrm{~g}$ for $30 \mathrm{~min}$ at room temperature, washed once in sterile phosphate-buffered saline (PBS) pH 7.3, and washed once in SDW. Tissues were stored in formol $10 \%$ saline. DNA was extracted in lysis buffer ( $50 \mathrm{~mm}$ Tris$\mathrm{HCl}$, pH 8.5, 1 mm EDTA, Tween $200.5 \%$ ) containing proteinase K (Sigma: final concentration $200 \mu \mathrm{g} / \mathrm{ml}$ ) at $55^{\circ} \mathrm{C}$ with shaking for $2.5 \mathrm{~h}$. The product was boiled for $10 \mathrm{~min}$ then stored at $-20^{\circ} \mathrm{C}$ before testing.

Twenty-three bronchoalveolar lavage (BAL), seven induced sputum (IS) and five tracheal aspirate (TA) samples from 19 patients with suspected clinical PCP were tested by an immunofluorescence assay (Shield Diagnostics) and PCR. For the PCR assay, the BAL, IS and TA samples were washed once in SDW then extracted with proteinase $\mathrm{K}$. Lithium-heparin blood samples were taken from two patients with laboratory and clinically diagnosed PCP and the buffy coats were prepared as for rat samples.

To produce a positive DNA control, $P$. carinii trophozoites were purified from infected rat lungs with a discontinuous Percoll gradient. ${ }^{8}$ Lungs were finely minced, washed four times in sterile PBS, and assessed for the numbers of cysts and trophozoites seen on staining. Parasite-rich washings were digested with collagenase $1.5 \mathrm{mg} / \mathrm{ml}$ in PBS- $1 \mathrm{~mm}$ EDTA at $37^{\circ} \mathrm{C}$ then centrifuged on a discontinuous Percoll gradient (36\%, 16\%, 8\% Percoll in PBS-1 mM EDTA) at $3000 \mathrm{rpm}$ for $15 \mathrm{~min}$. Trophozoite-rich fractions were chosen in preference to cyst-rich fractions because they were less contaminated with host cells. They were bulked, washed three times in sterile PBS and extracted by proteinase $\mathrm{K}$, followed by phenol:chloroform extraction (twice) and precipitated with ethanol. The DNA content of the sample was measured spectrophotometrically at $260 \mathrm{~nm}$.

Various organisms (Staphylococcus aureus, Aspergillus nidulans, $A$. versicolor, $A$. restrictus, Candida albicans, C. tropicalis, Klebsiella pneumoniae, Toxoplasma gondii and adenovirus) were tested to assess the specificity of the PCR. They were washed twice in PBS and extracted with proteinase $K$ at known concentrations. The samples were tested by PCR at two final concentrations $-10^{4}$ and $10^{3}$ organisms/sample.

\section{Polymerase chain reaction}

PCR was performed in two stages: a primary PCR followed by a nested PCR each in a total volume of $50 \mu \mathrm{l}: 20 \mu \mathrm{l}$ of sample and $30 \mu \mathrm{l}$ of the reagent mix (final concentration $10 \mathrm{~mm}$ Tris- $\mathrm{HCl}, \mathrm{pH} 8.5,50 \mathrm{~mm}$ $\mathrm{KCl}, 2.5 \mathrm{mM} \mathrm{MgCl}_{2}, 0.2 \mathrm{mM} \mathrm{dNTP}$, each primer $6 \mu \mathrm{g} / \mathrm{ml}$, Taq polymerase $0.7 \mathrm{units} / \mathrm{sample})$. The reaction buffer and Taq polymerase were supplied by Applied Biotechnologies, Cambridge and primers by Severn Biotech, Kidderminster. The dNTP contained equimolar dATP, dGTP, dTTP, dCTP (Pharmacia Biosystems Ltd, Milton Keynes). For the primary PCR, external primers PN1-5'-GATGGCTGTTTCCAAGCCCA-3' and PN2-5'-GTGTACGTTGCAAAGTACTC-3' (pAZ 102-E and pAZ 102-H respectively, described by Wakefield et $a .^{6}$ ) produced a product of $355 \mathrm{bp}$. The nested PCR primers PN1 and an internal primer PN3-5'-ATAAGGTAGATAGTCGAAAG-3' (equivalent to pAZ 102-L2 ${ }^{6}$ ) produced a 125 -bp product. Thermal cycling was done in a PHC3 Techne thermal cycling block (Scotlab) at $94^{\circ} \mathrm{C}$ for $1 \mathrm{~min}, 53^{\circ} \mathrm{C}$ for $1 \mathrm{~min}, 72^{\circ} \mathrm{C}$ for $1 \mathrm{~min}$ for 40 primary or 20 nested cycles with a final extension period of $5 \mathrm{~min}$ at $72^{\circ} \mathrm{C}$. For the nested PCR, the primary 
product was diluted 1 in 200 in SDW before testing and $\mathrm{dNTP}$ and Taq polymerase concentrations were reduced to $0.16 \mathrm{~mm}$ and 0.5 units/sample respectively. The nested PCR products were electrophoresed in agarose $2.5 \%$ gels containing ethidium bromide $1 \mu \mathrm{g} / \mathrm{ml}$ at $133 \mathrm{~V}$ for 30 min. $^{9}$

Buffy coats and human respiratory samples were tested at three dilutions: neat, 1 in 10 and 1 in 100; animal tissue samples were tested at 1 in 10,1 in 100 and 1 in 1000 to avoid inhibition of DNA amplification in neat samples. Buffy coat, liver, kidney and spleen samples were also seeded with $100 \mathrm{pg}$ of rat-derived $P$. carinii DNA and run in parallel with their equivalent unseeded samples. The PCR results of the unseeded tissues were acceptable only if the $P$. carinii DNA was detected in the seeded samples by PCR.

Precautions appropriate for the prevention of crosscontamination of the PCR assay were strictly adhered to; each stage of the assay was performed in separate rooms within the laboratory, negative controls were run in each assay, pipettes were regularly autoclaved and gloves were changed frequently.

\section{Statistical analysis}

The statistical analysis of the results of the PCR and the IFA on the respiratory samples was by the McNemar test. ${ }^{10}$

Table I. Results of blood and tissue samples from immunosuppressed rats assayed by nested PCR

\begin{tabular}{|c|c|c|c|c|c|c|c|c|c|}
\hline \multirow{2}{*}{$\begin{array}{l}\text { Rat } \\
\text { no. }\end{array}$} & \multicolumn{5}{|c|}{$\begin{array}{l}\text { Blood samples (days } \\
\text { immunosuppressed) }\end{array}$} & \multicolumn{4}{|c|}{ Tissue samples } \\
\hline & 14 & 21 & 28 & 37 & 42 & Lung & Liver & Kidney & Spleen \\
\hline 381 & ns & - & - & - & - & + & - & - & - \\
\hline 382 & ns & ns & - & - & - & + & - & - & - \\
\hline 383 & ns & - & - & ns & - & + & - & - & - \\
\hline 384 & - & - & - & ns & - & + & - & - & - \\
\hline 385 & - & - & - & ns & - & + & - & - & - \\
\hline 386 & - & - & ns & ns & ns & + & ns & ns & ns \\
\hline
\end{tabular}

Rat no. 386 died on day 25 of unknown causes; ns, no sample available to be tested; + , positive PCR; - , negative PCR.

Table II. Results of proteinase K-extracted human bronchoalveolar lavage, induced sputum and tracheal aspirate samples analysed by nested PCR and IFA

\begin{tabular}{lccccc}
\hline Specimen & $\begin{array}{c}\text { Number } \\
\text { of } \\
\text { samples }\end{array}$ & $\begin{array}{c}\text { IFA } \\
\text { positive }\end{array}$ & $\begin{array}{c}\text { PCR } \\
\text { positive }\end{array}$ & $\begin{array}{c}\text { IFA } \\
\text { negative }\end{array}$ & $\begin{array}{c}\text { PCR } \\
\text { negative }\end{array}$ \\
\hline BAL & 23 & 9 & 11 & 14 & 12 \\
IS & 7 & 2 & 3 & 5 & 4 \\
TA & 5 & 1 & 2 & 4 & 3 \\
Total & 35 & 12 & 16 & 23 & 19 \\
\hline
\end{tabular}

BAL, bronchoalveolar lavage; IS, induced sputum; TA, tracheal aspirate.

\section{Results}

The primary PCR produced an expected 355-bp product with the rat-derived $P$. carinii DNA control. After further amplification of the primary product with the internal primer PN3, a nested product of $125 \mathrm{bp}$, running to almost the same position as the 123-bp marker, was observed by ethidium bromide staining (figure). Amplification of human-derived $P$. carinii DNA was produced by the same oligonucleotides (figure). Serial dilutions of the ratderived $P$. carinii DNA were made and run in the PCR to determine its optimal sensitivity. The primary PCR consistently detected $590 \mathrm{pg}$ of $P$. carinii DNA; the nested PCR was up to 100 times more sensitive, detecting $5.9 \mathrm{pg}$ of $P$. carinii DNA. One $P$. carinii organism is considered to have a total of $10 \mathrm{fg}$ of DNA, ${ }^{11,12}$ thus the nested PCR detected the equivalent of 590 organisms. Proteinase K-extracted samples of various organisms were run in the PCR to assess its specificity (figure). No bands were observed in the target area for the nested run with extracts of the following organisms: $S$. aureus, A. nidulans, $A$. versicolor, A. restrictus, C. albicans, C. tropicalis, $K$. pneumoniae, adenovirus and $T$. gondii.

Twenty serial rat blood samples were available for testing by PCR, obtained by tail bleeds taken between 14 and 42 days of immunosuppression (table I). Rat 386 died on day 25 of immunosuppression, thus further bleeds were not possible. All of the 20 samples tested were negative by PCR. The seeded rat blood samples were positive by PCR. All of the lungs tested gave strong positive bands after amplification (table I). Each of the lungs was also positive by Toluidine blue-O and Giemsa staining demonstrating the presence of cysts and trophozoites. These were seen as early as 25 days of immunosuppression in the lung. The liver, kidney and spleen were available from five rats for testing. These were negative by PCR at all dilutions. The organs seeded with $100 \mathrm{pg}$ of $P$. carinii DNA were positive by PCR.

The results of the tests on the 35 clinical BAL, IS and TA samples are summarised in table II. Strongly amplified bands were detected in 12 samples. The IFA was strongly positive with nine of these samples ( $>20$ cysts/field) and three samples produced a borderline positive result (1-5 cysts/slide). Four samples from three patients (two BAL, one IS and one TA) were PCR-positive but IFA-negative. Statistical analysis showed that this difference was significant $(p<0.05$, McNemar test). The remaining 19 PCR-negative samples were IFA-negative. Buffy coats from two PCP-proven patients (PCR- and IFA-positive) were negative by PCR.

\section{Discussion}

The amplification of $P$. carinii DNA by the primers PN1 and PN2 has been used diagnostically in a 
single-step PCR assay ${ }^{3}$ or in combination with primer PN3 in the Southern blot hybridisation technique ${ }^{2-4}$ or nested PCR assay. ${ }^{5}$ We have developed a nested PCR with these primers which amplifies a product of $125 \mathrm{bp}^{13,14}$ The sensitivity of the assay was $5.9 \mathrm{pg}$ of $P$. carinii DNA or 590 organisms. In other reports, the sensitivity of the PCR protocol assays with the same primers is reported to be one or two organisms..$^{5,15}$ These assays were based on single-step PCR and Southern hybridisation ${ }^{5,15}$ and nested PCR. ${ }^{5}$ However, the method of preparation of control samples differed. In one instance, the parasites were counted after staining by Giemsa and methenamine silver $;{ }^{15}$ in the other, the counting method was not stated. ${ }^{5}$ Thereafter, serial dilutions were made and then run in their respective PCR protocols. There are sources of error whichever method is used to calculate sensitivity. In our experience it is difficult to identify parasites clearly after staining and, therefore, this method is likely to underestimate the number of parasites present and, consequently, overestimate PCR sensitivity. In contrast, our method, based on the DNA content of a purified parasite preparation, will underestimate the sensitivity to the extent that it contains contaminating host cell DNA. Although there is a difference in the sensitivities produced, the nested PCR protocol allows up to a 100 -fold increase over the sensitivity of the single-step assay, which is equivalent to the increase produced by Southern blot hybridisation. ${ }^{2,5}$ Other investigators used primers from the other genes and achieve sensitivities similar to, or poorer, than those reported here. ${ }^{11,12,16}$

$P$. carinii infection was detected in rat lungs from 25 days of immunosuppression as indicated by PCR and histological staining. There was no indication of disseminated infection in any of the other organs tested. Similarly, the results of this study indicate that there is no parasitaemia, and thus dissemination in rat leucocytes, up to and including 6 weeks of immunosuppression. However, very low numbers of parasites in these organs and blood samples may account for the negative PCR results. Also, only a relatively small proportion of organ and small volumes of tail bleed blood $(5-40 \mu \mathrm{l})$ were tested. Those workers who claimed greater PCR sensitivity did not detect parasitaemia before 6 weeks of immunosuppression. ${ }^{11}$

Disseminated infection has been observed later in immunosuppressed rats at 7 weeks of immunosuppression, ${ }^{11}$ and there has been one report of extrapulmonary infection in various organs from 2 weeks post-infection. ${ }^{17}$ This paper was later retracted..$^{18}$ The authors stated that the previously reported positive results may have been due to contamination of the samples or the radiolabelled probe. $P$. carinii DNA has been detected in leucocytes of rats by PCR ${ }^{3}$ However, the authors did not state at what time interval after immunosuppression the buffy coat samples were PCRpositive, although the lungs were confirmed as having $P$. carinii infection by histological staining. ${ }^{3}$ Parasitaemia has been detected at 6 weeks of immunosup- pression in rats fed a low protein diet. ${ }^{11}$ Such a diet is known to increase the intensity of the steroidinduced $P$. carinii infection ${ }^{19}$ and thus may produce a parasitaemia earlier. Indeed, when steroid treatment is stopped the parasitaemia in the sera disappears. ${ }^{20}$

In the Sprague-Dawley rat model, the early stages of $P$. carinii infection (up to 6 weeks) appear to be characterised usually by infection predominantly within the lung with little or no spread of the parasite within leucocytes. However, after longer immunosuppression or under more vigorous immunosuppressive regimes, disseminated infection may occur. Thus, detection of a blood parasitaemia may suggest ongoing $P$. carinii infection as a result of immunosuppression, ${ }^{19}$ rather than provide an early indication of infection.

As the nested PCR was able to detect both rat- and human-derived $P$. carinii DNA, it was used to test clinical samples. IFA positive BAL and IS samples were confirmed as positive by PCR. Indeed, three samples that were borderline positive by IFA were strongly positive by PCR. Furthermore, four samples from three patients were PCR-positive but IFAnegative. One BAL and the TA sample was from the same patient; the BAL was positive at neat and 1 in 10 dilution and the TA at neat only. This may indicate that a low level infection was detected by the more sensitive PCR technique. The IS was from a patient who was later confirmed to have PCP by IFA on a second sample. The other BAL was the last in a series of four samples from the same patient. The three previous samples were PCR and IFA positive. All these patients responded well to specific antipneumocystis therapy. It has been demonstrated that the single-step PCR with Southern blot hybridisation is between $10^{4}$ and $10^{6}$ times more sensitive than immunofluorescence with BAL samples. ${ }^{4}$ This may be due partly to the inherently greater sensitivity of the PCR but also in part to its ability to detect both trophozoite and cyst forms; the IFA and Toluidine blue-O staining are specific for cysts alone. Trophozoites are considered to outnumber cysts by 100:1 in PCP ${ }^{21}$ Thus the ability to detect both forms of the parasite may account for our observed increase in sensitivity. The nested PCR would appear to allow detection of PCP both earlier and for a longer period than by IFA, and in respiratory samples obtained by less invasive procedures. No parasites were detected in the leucocytes of two patients with PCP and these results are consistent with those found in the rat model.

This quick, sensitive and specific test has potential in dealing with clinical problems. Patients are often seriously ill in intensive-care units; a quick result allows early treatment and reduces the length of stay. These clinical and economic advantages suggest that such tests should be used more widely.

We are grateful to the clinicians for referring clinical specimens to us, J. Chatterton, D. Ashburn, L. Dargie and J. Steen for technical 
assistance and Miss L. Wycherley for secretarial assistance. This work was supported by the Scottish Home and Health Department,
Grant no. (K/MRS/50/C1828) and the Highland Health Board HIV/AIDS fund.

\section{References}

1. Chatterton JMW, Ho-Yen DO. Laboratory investigation of Pneumocystis carinii pneumonia. Genitourin Med 1992;68: 336-341.

2. Wakefield AE, Pixley FJ, Banerji $\mathrm{S}$ et al. Detection of Pneumocystis carinii with DNA amplification. Lancet $1990 ; 336: 451-453$.

3. Lipschik GY, Gill VJ, Lundgren JD et al. Improved diagnosis of Pneumocystis carinii infection by polymerase chain reaction on induced sputum and blood. Lancet $1992 ; 340$ : 203-206.

4. Leigh TR, Gazzard BG, Rowbottom A, Collins JV. Quantitative and qualitative comparison of DNA amplification by PCR with immunofluorescence staining for diagnosis of Pneumocystis carinii pneumonia. J Clin Pathol 1993; 46: $140-144$.

5. Tamburrini E, Mencarini $P$, De Luca A et al. Simple and rapid two-step polymerase chain reaction for diagnosis of Pneumocystis carinii infection. J Clin Microbiol 1993; 31 : 2788-2789.

6. Wakefield AE, Pixley FJ, Banerji S et al. Amplification of mitochondrial ribosomal RNA sequences from Pneumocystis carinii DNA of rat and human origin. Mol Biochem Parasitol 1990; 43: 69-76.

7. Chatterton JMW, Joss AWL, Williams H, Ho-Yen DO. Pneumocystis carinii antibody testing. J Clin Pathol 1989; 42: 865-868.

8. Chatterton JMW, Joss AWL, Pennington TH, Ho-Yen DO. Differences exist in the immunoblotting profiles of cyst and trophozoite antigens of Pneumocystis carinii. J Med Microbiol 1995; 42: 120-126.

9. Joss AWL, Chatterton JMW, Evans R, Ho-Yen DO. Toxoplasma polymerase chain reaction in experimental blood samples. J Med Microbiol 1993; 38: 38-43.

10. Daly LE, Bourke GJ, McGilvray J (eds). Interpretation and uses of medical statistics. 4th edn. London, Blackwell Scientific Publications. 1991: 130.

11. Schluger N, Godwin T, Sepkowitz K et al. Application of DNA amplification to pneumocystosis: presence of serum Pneumocystis carinii DNA during human and experimentally induced Pneumocystis carinii pneumonia. J Exp Med 1992; 176: 1327-1333.

12. Reddy LV, Zammit C, Schuman P, Crane LR. Detection of Pneumocystis carinii in a rat model of infection by polymerase chain reaction. Mol Cell Probes 1992; 6: 137-143.

13. Sinclair K, Wakefield AE, Banerji S, Hopkin JM. Pneumocystis carinii organisms derived from rat and human hosts are genetically distinct. Mol Biochem Parasitol 1991; 45 : 183-184.

14. Lee C-H, Lu J-J, Bartlett MS et al. Nucleotide sequence variation in Pneumocystis carinii strains that infect humans. $J$ Clin Microbiol 1993; 31 : 754-757.

15. Peters SE, Wakefield AE, Banerji S, Hopkin $M$. Quantification of the detection of Pneumocystis carinii by DNA amplification. Mol Cell Probes 1992; 6: 115-117.

16. Becker-Hapak M, Liberator P, Graves D. Detection of human Pneumocystis carinii by the polymerase chain reaction. J Protozool 1991; 38: 191S-194S.

17. Reddy LV, Zammit C. Proliferation patterns of latent Pneumocystis carinii in rat organs during progressive stages of immunosuppression. J Protozool 1991; 38: 43S-47S.

18. Reddy LV, Zammit C. Retraction (of above ${ }^{17}$ ). J Protozool $1992 ; 39: 648$.

19. Walzer PD. Experimental models of Pneumocystis carinii infections. In: Young LS (ed) Pneumocystis carinii pneumonia. Pathogenesis, diagnosis, treatment. New York, Marcel Dekker Inc, 1984: 7-76.

20. Sepkowitz K, Schluger N, Godwin T, Armstrong D, Cerami A, Bucala R. DNA amplification in experimental pneumocystosis: characterization of serum Pneumocystis carinii DNA and potential $P$. carinii carrier states. $J$ Infect Dis $1993 ; 168$ : $421-426$.

21. Chatterton JMW, Joss AWL, Davidson MM, Ho-Yen DO. Why have Pneumocystis carinii trophozoites been ignored? $J$ Clin Pathol 1990; 43: 265-268. 